\title{
Presencia y recurrencia de las Paremias en las Tradiciones peruanas de Ricardo Palma
}

\author{
Rosario Valdivia Paz-Soldán \\ Universidad Ricardo Palma, Lima - Perú \\ charysoldan@hotmail.com
}

\section{Resumen}

Ricardo Palma es un escritor que merece ser leído varias veces, analizado, estudiado, traducido. Y desde hace muchos años los críticos literarios e investigadores se han preocupado por estudiar la obra de nuestro tradicionista desde diversas perspectivas. Nuestro trabajo se centra en el análisis de las paremias en cinco tradiciones de Ricardo Palma.

Palabras clave: Tradición, paremias, refranes, aforismos, proverbios.

\section{Abstract}

Ricardo Palma is an author that deserves to be read, analysed, studied and translated several times. From many years now literary critics and researchers have been interested in studying the work of our traditionist from various approaches. Our paper is focused in analysing the proverbs from five traditions of Ricardo Palma.

Keywords: Tradition, proverbs, sayings, aphorisms, adages 
Rosario Valdivia Paz-Soldán, Licenciada en Traducción de la Universidad Ricardo Palma, magíster y doctora en Literatura Peruana y Latinoamericana de la Universidad Nacional Mayor de San Marcos. Actual Coordinadora de la Maestría en Traducción y Directora de la Biblioteca Central de la universidad Ricardo Palma. Obras: Traducción: Poemas de la morada de las Páginas de Camille Aubaude. (2011); La Traducción Literaria (2004); Traducciones de César Vallejo (2003); poemarios: Cuerpos en Concierto y Desconcierto (2000), Amores Virtuales, Desamores Reales (2008) y Amores Inconclusos (2017). Profesora visitante y conferencista internacional, ha ofrecido recitales de poesía en Francia, Italia, España, México, Bélgica, Cuba, Panamá, Uruguay, Argentina y otros. 
La obra de Ricardo Palma es una fuente inagotable de inspiración para cualquier estudioso. En especial, nos referimos a las Tradiciones Peruanas; se ha estudiado, por ejemplo, la importancia de los neologismos, de los términos en otros idiomas (francés, italiano, latín, entre otros), de la visión humorística del pasado, de ese fino humor que convierte en placentera su lectura.

También se ha estudiado a lo largo de estos años el tema de las crónicas como fuente de inspiración, la notoriedad que juega en las Tradiciones Peruanas los acontecimientos verídicos, la historia misma narrada a veces empleando eufemismos o, por el contrario, disfemismos.

Por otra parte, hay un consenso entre los críticos en relación al hábil manejo de la lengua, oscilando entre el uso del nivel superestándar hasta el nivel subestándar, cuando incluye poemas muy bien trabajados o jergas o habla popular, etc.

De la misma manera, se han publicado libros íntegros sobre el humor y la ironía así como del recurso de los sobrenombres con intención burlona que emplea al autor en sus Tradiciones. En este aspecto es digno de destacar la sátira religiosa y las caricaturas de ciertos personajes elegidos por Palma.

Igualmente, muchos estudiosos de la obra del tradicionalista han analizado el uso recurrente de personajes históricos, virreyes, incas o referentes literarios como Cervantes o Quevedo en torno a los cuales se ha entretejido la tradición, ofreciendo al lector un atisbo de nuestra historia y realidad peruanas.

En menor cantidad se ha hecho un estudio estadístico de todas las alusiones al lector, de esa complicidad entre autor y lector, estrategia poco empleada en aquel entonces y que ahora con mayor frecuencia es utilizada por los narradores. 
No obstante, sobre la presencia y recurrencia de las paremias en las Tradiciones Peruanas se ha escrito muy poco.

Tenemos conocimiento de un artículo titulado Refranes $y$ tradiciones en la obra de Ricardo Palma escrito por Isabelle Tauzin Castellanos de la Université Michel de Montaigne-Bordeaux (2006). En el mencionado libro se afirma que la edición Aguilar ofrece un recuento de 521 dichos, refranes y sentencias para el conjunto de las 453 tradiciones. Si bien aquel número no se puede comparar con los miles de proverbios recopilados en refraneros y sólo refleja un refrán por tradición, el estudio pormenorizado de dicho aporte palmista exige un espacio mayor al que le dedicó la escritora. Ella restringió su corpus de estudio a los títulos de las tradiciones que constituían refranes y sentencias.

Nuestra reflexión más bien se basa en la lectura y análisis de cinco Tradiciones Peruanas con sus respectivas paremias.

En primer lugar, analizaremos qué significa el término paremia. Según la especialista en paremias de la Universidad Complutense de Madrid, Julia Sevilla Muñoz ${ }^{1}$, la paremia es un archilexema, una unidad fraseológica (UF) constituida por un enunciado breve y sentencioso, que corresponde a una oración simple o compuesta, que se ha fijado en el habla y que forma parte del acervo socio-cultural de una comunidad hablante (v. Sevilla 1988, 2002, 2008, 2012). El universo paremiológico engloba los términos: proverbio, refrán, máxima, sentencia, frase proverbial, adagio, dialogismo, etc.

Es básico resaltar las características comunes de las paremias antes de revisar las Tradiciones donde ellas aparecen. Así, entre las características comunes encontramos la frecuencia de uso, la

I En nuestra bibliografía se puede encontrar varias obras de la mencionada investigadora. 
cual es gradual y oscila entre un uso "alto" y un "caer en desuso". También se observa un contenido sentencioso, una potencial idiomaticidad puesto que no todas las paremias tienen sentido metafórico, una potencial existencia de variantes que pueden ser diafásicas, diatópicas o diacrónicas en sus componentes estructurales o léxicos y una potencial pragmaticidad, o sea que el usuario según la circunstancia comunicativa puede otorgar a la paremia un significado situacional.

De otra parte, una primera gran división de las paremias tiene que ver con el origen, que puede ser conocido o anónimo, y con su uso, que puede ser culto o popular.

Las paremias de origen conocido son el proverbio y el aforismo. Un ejemplo de proverbio puede ser de naturaleza bíblica como: "El que esté libre de pecado que tire la primera piedra" (NT, San Juan 8,7). Hay varios subtipos de proverbios que no es menester profundizar en esta ocasión.

Por otra parte, un ejemplo de aforismo puede ser de corte ético como: "Sólo sé que nada sé" (Sócrates). Al respecto, no hay que olvidar que los aforismos son de procedencia culta observándose así el potencial conocimiento del autor. Los aforismos son atribuidos a personajes famosos, ya sean reales o ficticios. Podemos encontrar aforismos éticos, políticos y de origen científico o profesional.

En relación a las paremias de origen anónimo y de uso preferentemente popular, tenemos los refranes, las frases proverbiales, las locuciones proverbiales, los dialogismos. Por ejemplo, entre los refranes encontramos: "No dejes para mañana lo que puedes hacer hoy."

Ahora bien, las cinco Tradiciones Peruanas elegidas para nuestro estudio son aquellas en donde hemos encontrado más paremias. 
- Un virrey casamentero (Palma, 2015, pp. 349-352).

- La honradez de una ánima bendita (Ibídem, pp. 367-370).

- Lavaplatos (Ibídem, pp. 393-374).

- Al pie de la letra (Ibídem, pp. 459-463).

- Los panecitos de San Nicolás (Ibídem, pp. 37 1-375).

\section{Un virrey casamentero}

- Se va armar la gorda (expresión como sinónimo de un gran alboroto o se producirá un problema grave.)

- Tener a alguien por un pino de oro ( considerar a alguien muy valioso)

- Acampar como moros sin señor ( estar en desorden)

- Poner puñal al pecho ( amenazar de cualquier manera)

\section{La honradez de una ánima bendita}

- Ser más bueno que el pan de manteca (ser bondadoso)

- Tener dimes y diretes (locución verbal que hace referencia a comentarios y habladurías o a intercambio de opiniones, réplicas y contrarréplicas.)

\section{Lavaplatos}

- Hacerse la boca agua (una bonita expresión vinculada a que algo nos gusta mucho. Está relacionada con comida: se nos hace la boca agua delante de un plato delicioso, normalmente es en sentido irónico.)

- Echar la casa por la ventana (o tirar la casa por la ventana, es una frase de uso coloquial para expresar que alguien derrocha o gasta dinero sin control, ni medida). 
- No tener puntada sin nudo; no dar puntada sin hilo (se dice que "no da puntada sin hilo" cuando todo lo que alguien dice o hace tiene algún objetivo o intención, normalmente beneficioso para sí, que previamente ha planeado).

\section{Al pie de la letra}

- Inventar la pólvora (cuando hablamos de alguien poco inteligente o de quien dice una obviedad (en ambos casos se usa); es frecuente decir, "este va a inventar la pólvora".

- Empinar el codo (significa beber en exceso. Su uso proviene de la costumbre de inclinar la bota de vino para beber. También se usaban las expresiones "levantar el codo", "alzar el codo" o "beber el codo". En el siglo XVI existía otra expresión muy similar que era "empinar el jarro", usado cuando se terminaba toda la bebida.)

- Entre dos luces ( al rayar el alba)

\section{Los panecillos de San Nicolás}

- Creer a pies juntillos ( creer al pie de la letra)

- Asomar las narices ( estar merodeando, meterse en donde no lo han llamado)

- No entender jota ( no entender nada en absoluto)

- Ser el pan nuestro de cada día ( tener la misma experiencia siempre)

- Cerrar con llave de oro (ser el último en una actuación o actividad y hacerlo con mérito). 
Aquí abundan las referencias eclesiásticas y el fino humor del tradicionista como cuando un chico pregunta a su abuela: ¿Por qué pides a Dios todas las mañanas el pan nuestro de cada día? ¿No sería mejor, abuelita, que pidieses por junto siquiera para un mes? No hijo -contestó la vieja-: se pondría muy duro para mis quijadas, y a mí me gusta el pan tierno y calientito (Ibídem, p. 374).

Por ahora ponemos fin a nuestra reflexión con la cual hemos querido abrir una línea de investigación en donde hay mucho trabajo por hacer: revisar las Tradiciones Peruanas, seleccionando las paremias, clasificándolas, contextualizándolas e interpretándolas y por qué no traduciéndolas a otros idiomas.

\section{Referencias bibliográficas}

Palma, R. (2015). Tradiciones Peruanas. Rodríguez, M. (ed.). Séptima/ Octava Series. Tomo I. Vol. IV. Lima: Universidad Ricardo Palma.

Sevilla, J. (1988). Hacia una aproximación conceptual de las paremias francesas y españolas. Madrid: Editorial Complutense.

(2002). "El refrán: síntesis de experiencia". En La palabra. Expresiones de la tradición oral. Salamanca: Centro de Cultura Tradicional. Diputación de Salamanca.

(2008). Formas paremiológicas y criterios de clasificación. En Critica del testo, XI/1-2, 235-248. Recuperado el 14 de marzo de 2019, de https://cvc.cervantes.es/lengua/paremia/pdf/022/009_sevilla-crida. pdf.

(2012). ¿Tanto va el cántaro a la fuente que... encuentra un universal paremiológico?, Les Cahiers de Framespa [Univ. Toulouse], 10, 2012, Recuperado el 14 de marzo de 2019, de http://framespa. revues.org/1641 
Tauzin, I. (2006). Refranes y tradiciones en la obra de Ricardo Palma. Buenos Aires: Biblioteca Virtual Universal. Recuperado el 14 de marzo de 2019, de http://www.biblioteca.org.ar/libros/134658.pdf. Facilitado por la Biblioteca Virtual Miguel de Cervantes.

Recibido el 13 de marzo del 2019 Aceptado el 14 de marzo del 2019 